\title{
Un enorme ejercicio de estilo: Matías Battistón y su traducción de la trilogía beckettiana
}

Sobre la trilogía Molloy, Malone muere y El innombrable, Buenos Aires: Ediciones Godot, 2016, 2020 y 2020 respectivamente, traducción Matías Battistón.

$(3$

Reportaje de Lucas Margarit

Universidad de Buenos Aires, Argentina
Acaba de salir publicada -bajo el sello de la editorial Godot- la trilogía de Samuel Beckett formada por las novelas Molloy (1951), Malone muere (1951) y El innombrable (1953). En el año 2016 la editorial ya había publicado la tercera novela de la serie (publicada en ese orden por temas contractuales) y en julio de este año completa la trilogía con la publicación de las otras dos. Sin dudas, sabemos que es un acontecimiento importante por varias razones, en primer lugar, una actualización de las versiones anteriores publicadas en Argentina (Sur, 1958, 1961) o España (ed. Lumen y Alianza), por otro lado, la tarea de un solo traductor, Matías Battistón, brinda una evidente continuidad en estas nuevas versiones realizadas desde el francés.

Battistón conoce muy bien la obra de Beckett, la ha frecuentado en detalle, lo cual es notable en su manera de pensar el traslado a nuestra lengua. Estas versiones dan en muchos aspectos con el tono necesario para hacerlo de la manera más fiel el texto en francés, sobre todo en uno de los aspectos que creemos fundamentales en el momento de hacer una puesta en escena, de leer o de traducir -como en este caso-, la obra beckettiana: el ritmo. Editorial Godot a través de estas traducciones nos brinda la oportunidad de acercarnos nuevamente al prosista Beckett en una de las narraciones más destacadas del siglo XX.

Debemos agregar también que esta traducción puede pensarse como parte de una nueva generación de versiones de la obra de Beckett -tal como nos lo cuenta Battistón- donde se tienen en cuenta otros aspectos de la traductología (comparar versiones, cotejar los originales de las versiones de Beckett, confrontar manuscritos, etc.), lo que sin duda enriquece el trabajo del traductor en muchos aspectos y no se presenta como una versión mecánica del traslado de una lengua a otra.

La publicación de esta nueva traducción sigue manifestando la enorme vigencia de la obra de Beckett tanto en nuestro medio editorial y cultural como en el resto del mundo hispanoparlante, tal como se ha manifestado en los dos últimos congresos de la Samuel Beckett Society, en Ciudad de México y en Almería, España.

Para reseñar este acontecimiento editorial hemos dialogado con el traductor, Matías Battistón, donde nos cuenta su derrotero como traductor y su relación con la obra de Beckett y donde comenta estas traducciones que estamos presentando.

\section{¿Cómo fueron tus comienzos como traductor y} más en particular como traductor de literatura?

Hace unos años empecé a enviar proyectos a distintas editoriales independientes, para proponerles libros que me parecía que irían bien dentro de sus catálogos y de los que todavía no había versión en castellano. Pocos de esos primeros proyectos se terminaron haciendo (una de las excepciones fue Obras de Édouard Levé, justamente un libro sobre proyectos no realizados, que traduje años después), pero en realidad sirvieron para establecer un campo de intereses compartidos, digamos. Así empecé a hablar con distintos editores, que a su vez me empezaron a proponer también cosas para traducir a mí, y se armó un ida y vuelta. Beckett fue algo que me propusieron los chicos de Ediciones Godot cuando ya habíamos hecho varios libros juntos.

\section{¿Qué otros autores además de Samuel Beckett has traducido?}

A John Cage, a Flaubert, a Ed Wood, a Proust, a John Waters, a Gertrude Stein, a James Stephens, a Roland Barthes, a W.B. Yeats, a Édouard Levé... Como dirían en el noticiero, son muchos los damnificados.

¿Podrías comentarnos acerca de tu estancia como traductor en residencia en el Trinity College de Dublín y de los documentos manuscritos que 
has consultado? ¿De qué modo interviene esta investigación de documentos en la traducción?

Estuve cuatro meses viviendo en el campus de Trinity, que, a diferencia de muchas universidades extranjeras, está en el corazón mismo de la capital. Ahora, si bien en Trinity hay varios manuscritos físicos de Beckett, lo que más me sirvió en este proyecto fue que me dieron acceso al Beckett Archive, un proyecto de digitalización muy ambicioso que, además de recabar los distintos borradores, y de mostrarlos con lujo de detalles (con sus respectivas tachaduras, garabatos, alternativas, etc. $)^{1}$, los acompañan de estudios genéticos muy minuciosos, donde se señala y explica, por ejemplo, las diferencias genéticas entre las versiones preliminares en un idioma y en otro, desde los primeros esbozos hasta los últimos tapuscritos. En libros con tantas capas como los de Beckett, tener acceso a esas partes ocultas y dejadas de lado es invaluable, porque ayuda a darle otro sentido a las huellas que quedaron en las versiones finales. Además, uno puede ver los dibujitos deformes que hizo con birome en sus cuadernos. Eso ya no sé cómo interviene en la traducción, pero interviene.

Esta edición es una traducción de la trilogía del francés. Me has comentado que también habías llevado a cabo una versión del inglés. ¿Por qué la elección para la publicación? ¿Qué diferencias encontraste?

El contrato fue para la versión de Éditions de Minuit, y la idea de traducir de forma íntegra la otra (la autotraducción de Beckett al inglés) se me ocurrió cuando mis traducciones del francés ya estaban avanzadas. Así que lo más natural fue publicar esas, las francesas. Me gustaría en cualquier caso que en algún momento circularan las dos, las que traduje del francés y las que traduje del inglés. Las diferencias, más allá de las que evidentemente se deben a la naturaleza misma de cada lengua, en general son menos pirotécnicas que las que uno encuentra en otros autores que también se autotradujeron, o que colaboraron en las traducciones de sus propias obras, como Cabrera Infante o Nabokov, donde hay más expansiones y virtuosismo. Beckett suele hacer cambios relativamente menores de una versión a la otra en la Trilogía, pero que de algún modo son más chocantes, como amputar frases y párrafos, oscurecer

\footnotetext{
1. El proyecto Beckett Archive Digital Manuscript Project reúne documentos y manuscritos de Beckett de los principales archivos de diferentes universidades e instituciones (Trinity College de Dublín, Universidad de Reading en Inglaterra o el Harry Ransom Center de la Universidad de Texas). Sus directores son Dirk Van Hulle and Mark Nixon.
}

o enrarecer el tono ("I'avenir" pasa a ser "the scytheman", "la nature" se convierte en "this fucking scenary", "ces histoires" termina siendo "balls"), o filtrar alusiones muy sutiles, incluso haciendo que ambas versiones "dialoguen" entre sí.

Uno de los aspectos importantes de la obra de Beckett es el ritmo que el texto va desplegando en su desarrollo. ¿Tuviste en cuenta este detalle? ¿Cómo es llevarlo a cabo en el español?

Claro, el ritmo es vital. Traté de ser lo menos sordo posible. Para eso también fui cotejando su autotraducción al inglés con el original en francés, para ver cómo seguía él mismo su propia cadencia de un idioma a otro, cuánto se despegaba y cuánto estaba dispuesto a sacrificar para no despegarse. Con esos detalles enloqueció a Patrick Bowles, que era el cotraductor original de Molloy, y a muchísimos actores y actrices, claro. Al mismo tiempo, en la Trilogía el texto todavía respira, así que no fue un ejercicio tan asmático como sería traducir sus últimas piezas de teatro, por ejemplo.

¿Encontrás diferencias consistentes de una novela a otra en el momento de traducir la trilogía con respecto a las características del uso del lenguaje en Beckett?

Sí, veo una degradación pronunciada, en el sentido de que, con el paso de una a la otra, las historias se van fragmentando todavía más, se van haciendo más turbias, empiezan a chapotear entre las palabras en vez de moverse. Si en Molloy la narración se quiebra y se filtran, por así decirlo, momentos de puro lenguaje, ya al final, en El innombrable, lo que hay es un maremágnum de lenguaje por donde se filtran pedazos de narraciones. Hay como un virtuosismo de la incertidumbre que se va imponiendo.

¿Cómo ubicarías tus versiones en el marco de la tradición en la traducción de las obras beckettianas?

A mí me gusta la línea mutante que empieza Paulo Leminski, que traduce Malone morre mechando el inglés y el francés, con el ojo puesto en las posibilidades que ofrece el bilingüismo de la obra. Si bien yo no las mezclo, me atrae esa curiosidad, esas ganas de hacer otra cosa. La idea de hacer dos versiones paralelas, aunque una quede oculta, tiene, espero, algo de eso. Después me enteré de que Chiara Montini hizo algo similar a lo que hice yo pero en italiano, con Mercier e Camier, así que esto quizá sea parte de las 
últimas camadas de retraducciones de Beckett, o una veta dentro de esas camadas.

Hay un antecedente importante con respecto a la traducción de Malone muere, que es la traducción que hizo José Bianco para la ed. Sur en 1958. ¿Podrías comentar si la leíste y que diferencias encontraríamos entre tu versión y la de Bianco?

Claro, la leí. Es muy buena, y tiene grandes aciertos (hasta diría ciertas marcas de estilo, como traducir "cherchons un autre joint" por "busquémosle otra vuelta"). Pero al mismo tiempo uno siente, en parte, que está hecha con algo de apuro, y quizá de distancia. Bianco omite oraciones, a veces una después de la otra, seguramente por distracción. Más particular es que desaparecen varios, o creo que directamente todos, los neologismos de Beckett en ese libro, que están en esas oraciones omitidas. Nada que Bianco no habría podido traducir casi a vuela pluma, si lo hubiera visto, o si alguien se lo hubiera señalado, así que todo indicaría que es más bien un efecto de la falta de revisores de Sur (traductores eximios y revisores inexistentes parecía ser uno de los pilares de la editorial). También hay un vaivén dialectal más marcado en Bianco, que habla de "coños" en un momento y de "puchos" en otro, por ejemplo. Y al no cotejar con el texto inglés de Beckett, que en muchos casos sirve de explicación o paráfrasis, varias de las frases más ambiguas a Bianco se le vuelven, creo, demasiado misteriosas. Pero repito que es una muy buena traducción, y desde luego tiene algo que la mía no tiene, que es a José Bianco.

¿Creés que existe algún punto de contacto entre el español de las orillas, es decir el de Buenos Aires y el francés de Beckett en tanto lenguas descentradas?

Claro. Cuando Beckett mete la mano y encuentra en el argot francés la palabra "cache-misère", y uno desde Buenos Aires puede estirar la suya y encontrar, en el lunfardo, la palabra "tapamugre", ahí tenemos un ejemplo específico, tirando a miope, de contacto entre dos lenguas. Ahora bien, si hablamos en términos de lenguas descentradas, o excéntricas, creo que el verdadero vínculo entre el francés de Beckett y el castellano rioplatense es menos la lengua en sí que cómo se la percibe, cómo se la escucha. Es decir, con sospecha. La sospecha que genera lo que nunca termina, en un sentido u otro, de adaptarse.

\section{Para cerrar, ¿por qué hoy la obra de Beckett es necesaria? ¿Por qué una nueva traducción?}

Hay muchas cosas que hacen que Beckett sea un escritor único, y que justifican, creo yo, después de tantos años, una traducción nueva que vuelva a ponerlo en circulación, que permita establecer otros vínculos. Pero la verdad es que no soy muy creyente en la necesidad, en las lecturas necesarias. Todo autor se lee mejor cuando uno siente que lo eligió menos por obligación que por capricho, ¿no? Así que cambiaría la pregunta: ¿por qué encapricharse con Beckett? Y creo que para ese tipo de pregunta la mejor respuesta, quizá por ser la más antisatisfactoria, siempre es en el fondo la misma: porque sí. 